\title{
Effect of CYP1A1 and GSTM1 genetic polymorphisms on bone tumor susceptibility
}

\author{
L. Li' ${ }^{1}$, J.G. Li ${ }^{2}$, C.Y. Liü ${ }^{2}$ and Y.J. Ding ${ }^{1}$ \\ ${ }^{1}$ Division of Bone and Joint Surgery, \\ Jinan Central Hospital Affiliated to Shandong University, Jinan, China \\ 'Division of Bone and Joint Surgery, Zhangqiu People's Hospital, Jinan, \\ Shandong, China
}

Corresponding author: J.G. Li

E-mail: shishangniu456@163.com

Genet. Mol. Res. 14 (4): 16600-16607 (2015)

Received August 26, 2015

Accepted October 11, 2015

Published December 11, 2015

DOI http://dx.doi.org/10.4238/2015.December.11.7

ABSTRACT. Tumorgene polymorphisms are often associated with individual susceptibility to genetic diseases. Cytochrome P4501A1 (CYP1A1) and glutathione S-transferase mu 1 (GSTM1) gene polymorphisms are closely related to the susceptibility of the body to chemical carcinogens in the environment. Therefore, we explored the relationship between CYP1A1 and GSTM1 gene polymorphisms and susceptibility to bone tumors. Multiplex-polymerase chain reaction (PCR), allelic-specific PCR, and PCRrestriction fragment length polymorphism techniques were used to analyze CYP1A1 and GSTM1 gene polymorphisms in 52 bone tumor patients and 100 healthy subjects. The allelic variation frequency of the CYP1A1 gene at exon 7 (lle $462 \mathrm{Val}$ ) in bone tumor patients was 0.462 , which was significantly higher than that in the normal controls $(0.223)$. The frequency of the absence of the GSTM1 homozygous genotype in the patients (0.65) was also markedly higher than that in the control group (0.41). Subjects with CYP1A1 Val/Val homozygous mutations and absence of the GSTM1 homozygous genotype were at markedly increased risk of developing bone tumors [ORs $4.15(95 \% \mathrm{Cl}: 1.268-13.30)$ and $2.35(95 \% \mathrm{Cl}: 1.15-$ 
4.85), respectively]. The OR for the combined effect of the CYP1A1 and GSTM1 gene polymorphisms was 8.55 (95\%Cl: 1.75-41.50). CYP1A1 and GSTM1 polymorphisms are genetic risk factors in patients with bone tumors, and the allelic variation of these genes increases the risk of bone tumor occurrence.

Key words: Bone tumor; CYP1A1; GSTM1; Genetic susceptibility; Genotype

\section{INTRODUCTION}

Osteosarcoma, also known as osteogenic sarcoma, is characterized by tumor cells that can produce the osteoid matrix. It is the most common primary malignant bone tumor and accounts for about 35\% of all such tumors (Ottaviani and Jaffe, 2009). Although osteosarcoma appears in all age groups, it is most prevalent in adolescents (Chou and Gorlick, 2006). Osteosarcoma can occur in any part of the skeleton. Though bone sarcoma is uncommon compared with other malignant tumors, it nevertheless has a high incidence rate and features early distant metastases. It is the second most common fatal tumor in individuals under 20 years of age (Wittig et al., 2002; Gorlick et al., 2003; Jaffe, 2009). Following the emergence of neoadjuvant chemotherapy and the improvement of surgical techniques, the 5-year survival rate for osteosarcoma has increased from 20-30 to 70\% (Wittig et al., 2002; Sánchez-Tilló et al., 2012). In recent years, however, the treatment of osteosarcoma has not improved significantly. About $30 \%$ of patients without metastasis at the first visit die of lung metastases (Sánchez-Tilló et al., 2012).

The majority of environmental carcinogens do not directly cause cancer. They can only form carcinogenic electrophilic compounds with strong polarity after catalysis by phase I metabolism enzymes such as cytochrome P450, while such compounds can be changed to nontoxic hydrophilic compounds through catalysis by phase II metabolism enzymes such as glutathione S-transferases (GSTs). Metabolic enzyme gene polymorphisms may change enzyme function, leading to increased vulnerability to external environmental risk factors and increased cancer risk. Environmental carcinogens may correlate with most of the susceptibility to tumors, genetic polymorphisms leads to a significant difference in host in response to different carcinogenic factors. Genetic polymorphism of biotransformation enzymes plays a key role in the carcinogenic effect of environmental carcinogens by initiating the processes involved in cancer (Taningher et al., 1999). Relevant research has indicated that the interaction between multiple metabolic enzymes and substrates is still not clear owing to the complicated carcinogenic process involving environmental carcinogens. Along with regional, individual, and ethnic differences, as well as differences in the method of detection used, conclusions about the relationship between tumor susceptibility and metabolic enzyme gene polymorphisms also differ (Nakazato et al., 2003). It has been found that phase I and II metabolic enzyme polymorphisms are associated with susceptibility to several types of cancer such as lung, breast, head and neck, and bladder cancer (Wang et al., 2003).

GSTs are phase II metabolic enzymes belonging to the multi-function dimer protein family. They are encoded by the GST-mu family of genes that locates in the chromosomal locus $1 \mathrm{p} 13.3$ (Abu-Amero et al., 2006). CYP450 is a phase I metabolic enzyme that belongs to a super family of proteins. It can convert procarcinogens into electrophilic compounds that attack DNA or proteins in cells; this can alter oncogenes or tumor suppressor genes and eventually lead to cancer (Jonsson et al., 2004). It has been reported that the GSTM1 gene polymorphism is associated with an 
increase in susceptibility to a variety of tumors (Mannervik and Danielson, 1988; Kiyohara et al., 1998). Moreover, GSTM1 homozygosity rates vary in different populations, which leads to varying cancer probability (Hayes and Strange 2000; Schabath et al., 2005).

CYP1A1 is a subtype of CYP450. Studies have shown that CYP1A1 and GSTM1 polymorphisms are closely associated with susceptibility to mutagenic materials in the environment. Therefore, cell canceration is closely related to the activity of these two enzymes and their relative levels (Yang et al., 2005; Gonzalez and Yu, 2006; Yang et al., 2007).

Therefore, we explored the relationship between CYP1A1 and GSTM1 genetic polymorphisms and bone tumor susceptibility in patients, with the aim of providing a basis for diagnosis and treatment.

\section{MATERIAL AND METHODS}

\section{Clinical samples}

Fifty-two bone cancer patients were enrolled from our hospital, and their diagnoses were confirmed by pathological investigation. Another 100 healthy subjects were selected as controls. The age, gender, nationality, and place of residence of the subjects were compared.

The study protocol was approved by the Research Ethics Committee of our hospital, and all patients gave their informed consent before study commencement.

\section{DNA extraction}

Venous blood $(5 \mathrm{~mL})$ was extracted from each subject and the serum was separated by centrifugation. DNA was extracted from the blood according to the method described in the literature (Jaffe, 2009) After confirming that the optical density was above 1.8, the sample was diluted to $200 \mu \mathrm{g} / \mathrm{mL}$ and stored at $-20^{\circ} \mathrm{C}$.

\section{Genotype detection}

Primers were synthesized by the Shanghai Sangon Biological Company. The buffer and Taq enzyme were bought from the Shanghai Bocai Biotechnology Company. The polymerase chain reaction (PCR) was performed on a Bio-Rad 700 gene amplification system (Hercules, California, USA). The PCR-restriction fragment length polymorphism (RFLP) method was applied to detect the CYP1A1d Msp1 polymorphism, and the specific allele primer was as follows: forward, 5'-ACAGTGAAGAGGTGTAGCCGCTG-3'; reverse, 5'-TTAGGAGTCTTGTCTCATGCCTA-3'. The cycling conditions for the amplification of the CYPIA1 gene comprised an initial single cycle of $5 \mathrm{~min}$ at $94^{\circ} \mathrm{C}$; 30 cycles of $30 \mathrm{~s}$ at $94^{\circ} \mathrm{C}, 30 \mathrm{~s}$ at $54^{\circ} \mathrm{C}$, and $30 \mathrm{~s}$ at $72^{\circ} \mathrm{C}$; and an extension of $10 \mathrm{~min}$ at $72^{\circ} \mathrm{C}$. The product was stored at $-4^{\circ} \mathrm{C}$. The PCR product of the Msp1 loci on the CYPIA1 gene was digested using Msp1 enzyme at $37^{\circ} \mathrm{C}$ for $14 \mathrm{~h}$. Allele-specific PCR was used to detect the 7th exon A4889G polymorphism in CYP1A1. The primers used were as follows: forward, 5'-AAGACCTCCCAGCGGGCAAT-3' and 5'-AAGACCTCCCAGCGGGCAAC-3'; reverse, 5'-CTCTGGTTACAGGAAGCTAT-3'. The cycling conditions comprised an initial single cycle of 5 min at $95^{\circ} \mathrm{C}$; 35 cycles of $60 \mathrm{~s}$ at $95^{\circ} \mathrm{C}, 60 \mathrm{~s}$ at $64^{\circ} \mathrm{C}$, and $120 \mathrm{~s}$ at $72^{\circ} \mathrm{C}$; and an extension of $5 \mathrm{~min}$ at $72^{\circ} \mathrm{C}$. Multi-PCR was performed to determine GSTM1 allelic loss, and $\beta$-globin was selected as a control. The primers used were as follows: GSTM1 forward, 5'-GTTGGGCTCAAATATACGG 
TGG-3'; reverse, 5'-CAACTCCCTGAAAAGCTAAAGC-3'; $\beta$-globin forward, 5'-GAAGAGCCAAGG ACAGGTAC-3'; reverse, 5'-CAACTTCATCCACGTTCACC-3'. The cycling conditions comprised an initial single cycle of $5 \mathrm{~min}$ at $95^{\circ} \mathrm{C} ; 35$ cycles of $60 \mathrm{~s}$ at $95^{\circ} \mathrm{C}, 60 \mathrm{~s}$ at $64^{\circ} \mathrm{C}$, and $120 \mathrm{~s}$ at $72^{\circ} \mathrm{C}$; and an extension of $5 \mathrm{~min}$ at $72^{\circ} \mathrm{C}$.

\section{Statistical analysis}

All statistical analyses were performed using SPSS11.5 software (Chicago, IL, USA). Differences between multiple groups were analyzed using the $t$-test or the chi-square test. The chisquare test was used to calculate odds ratios (ORs) and $95 \%$ confidence intervals $(95 \% \mathrm{Cls})$. A P value $<0.05$ was considered a statistically significant difference.

\section{RESULTS}

\section{CYP1A1 polymorphism distribution}

The PCR product length of the CYPIA1 gene Msp1 loci was $343 \mathrm{bp}$. There were three digestion types: TT, T/C, and C/C. The CYP1A1 exon 7 polymorphism distribution was significantly different in the two groups $(P<0.01)$. CYP1A1 Val/Val homozygosity mutation frequency $(0.462)$ in the bone tumor patients was significantly higher than in the control group (0.223), while the subjects carrying the CYP1A1 Val/Val genotype had 4.13 times higher risk of suffering bone cancer than those carrying the CYP1A1 lle/lle genotype (Figure 1 and Table 1).

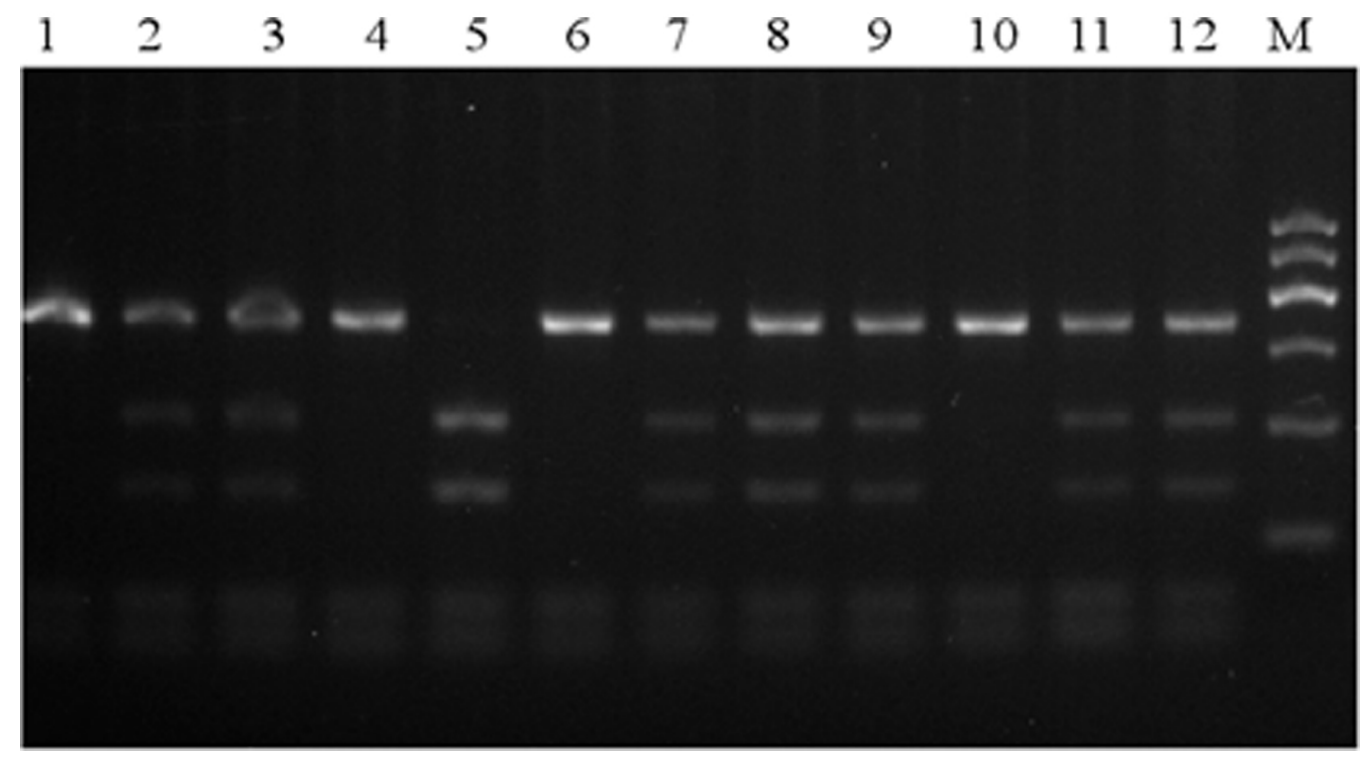

Figure 1. PCR detection of CYP1A1 gene in patients with bone cancer. Lanes 1, 4, 6, 10 (type TT); lanes 2, 3, 7, 8, 9, 11, 12 (type T/C); lane 5 (type C/C). 
Table 1. CYP1A1 polymorphism distribution.

\begin{tabular}{lccc}
\hline CYP1A1 genotype & Case & Control & OR $(95 \% \mathrm{Cl})$ \\
\hline Val/Val & 7 & 6 & $4.15(1.26-13.30)$ \\
Val/le & 25 & 34 & $2.35(1.15-4.85)$ \\
lle/lle & 20 & 60 & \\
\hline
\end{tabular}

\section{GSTM1 polymorphism distribution}

The GSTM1 gene polymorphism was either present or absent. Gene deletion could not be amplified by PCR. The PCR product of GSTM1 was $313 \mathrm{bp}$, while the $\beta$-globin length was $268 \mathrm{bp}$. Homozygosity of GSTM1 deletion accounted for $65 \%$ of cases and $41 \%$ of controls, and the difference was significant $(P<0.05)$. Subjects with homozygosity of deletion had a 2.72-fold increased risk of bone cancer (Figure 2, Table 2).

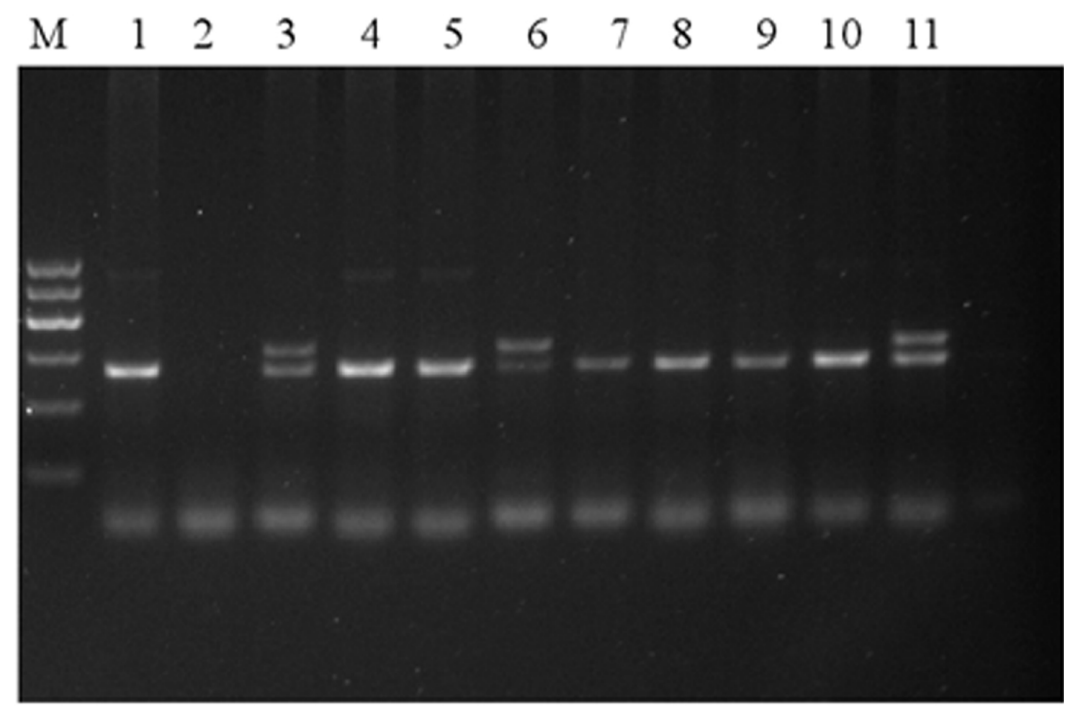

Figure 2. PCR detection of GSTM1 gene in patients with bone cancer. Lanes 3, 6, 11 (GSTM1+/+); lanes 1, 4, 5, 7, 8, 9, 10 (GSTM1-/-).

Table 2. GSTM1 polymorphism distribution.

\begin{tabular}{lccc}
\hline GSTM1 genotype & Case & Control & OR $(95 \% \mathrm{Cl})$ \\
\hline- & 36 & 42 & $2.70(1.32-5.43)$ \\
+ & 16 & 37 & -
\end{tabular}

Analysis of the combined effect of CYP1A1 and GSTM1 polymorphisms

Crossover analysis was applied to calculate ORs, with CYP1A1 lle/lle and GSTM1 (+) acting as the negative control. As shown in Table 3, the OR of CYP1A1 Val/lle combined with GSTM1 (-) was 6.82 and the OR of CYP1A1 Va1/Va1 combined with GSTM1 (-) was 8.55. The two gene mutations exhibited significant synergistic effects (Table 3 ). 


Table 3. Combined effect of CYP1A1 and GSTM1.
\begin{tabular}{lcccc} 
\\
CYP1A1 genotype & GSTM1 genotype & Case & Control & OR (95\%Cl) \\
\hline Ile/lle & + & 8 & 36 & 1.00 \\
Val/lle & + & 8 & 20 & $1.40(0.50-4.74)$ \\
Val/Val & + & 3 & 4 & $2.85(0.40-19.85)$ \\
Ile/lle & - & 10 & 26 & $1.83(0.66-5.05)$ \\
Val/lle & - & 18 & 12 & $6.82(2.23-20.52)$ \\
Val/Val & - & 5 & 2 & $8.55(1.75-41.50)$ \\
\hline
\end{tabular}

\section{DISCUSSION}

The cytochrome P450 (CYP) family, which are phase I metabolic enzymes, are important in the metabolism of endogenous and exogenous compounds. They mainly exist in the endoplasmic reticulum of liver and intestine cells, and are monooxygenases that catalyze the metabolism of numerous internal and external substances. The CYPIA1 gene encodes enzymes that are involved in the activation and metabolism of a variety of environmental carcinogens (Wang et al., 2003) (WangZheng, 2003). The CYPIA1 gene has a polymorphism, namely, the exon 7 A-G variation, which can change the encoded enzyme (lle to Val at amino acid 462) and reduce the ability of the body to process and metabolize carcinogens (Amundadottir et al., 2004; Larsen et al., 2005; Masson et al., 2005).

The Msp1 locus has three genotypes: the homozygous type (T/T), the hybrid type (T/C), and the wild type $(\mathrm{C} / \mathrm{C})$. Msp1 locus mutation $(\mathrm{T} \rightarrow \mathrm{C})$ of CYPIA1 gene causes structural change at the 31 flank area. This change not only influences the iron ion electron transfer ability of the CYPIA1 gene product but also affects protein interactions that leads to the inhibition of transcription of proto-oncogene and tumor suppressor gene, since the CYPIA1 gene participates in protein and gene transcription. This increases tumor susceptibility. However, the correlation between the effect of the CYPIA1 gene and tumor susceptibility was inconsistent, which suggests that although tumor susceptibility is closely associated with gene polymorphism, any kind of gene polymorphism can dominate tumor occurrence. Our study also confirmed that the CYP1A1 gene Msp1 loci polymorphism exists as three genotypes in osteosarcoma. We also found that the A4889G loci allele mutation frequency $(0.462)$ in osteosarcoma was higher than that in the control $(0.223)$, causing an osteosarcoma risk increase of 4.13 fold in subjects carrying the CYP1A1 Val/Val homozygous genotype. This indicates that CYP1A1 genetic polymorphism is an osteosarcoma pathogenic factor, and is associated with osteosarcoma susceptibility.

GSTs, which are phase II metabolic enzymes, are composed of soluble dimer proteins, and mainly exist in liver tissue. Their isozymes play an important role in anti-oxidation during cell injury, and they help resist foreign compound invasion (Kiyohara et al., 1998). At present, the different results regarding GST gene polymorphism and cancer susceptibility in China are mainly due to differences in race and region. Based on different races, regions, and cancers, Kidd et al. (2003), Kote-Jarai et al. (2001), Beer et al. (2002), Marchand et al. (1999), and Mitra et al. (2006) suggested the following: the GSTM1 gene polymorphism is not involved in prostate cancer in Europe; deletion of the GSTT1 genotype is a risk factor for prostate cancer in Europeans; the GSTP1 gene polymorphism is correlated with stomach cancer occurrence in Caucasians; and the GSTM1 gene polymorphism is not related to bladder cancer occurrence in the United States. Our results further confirm that expression of the same genes varies in different races, regions, and tissues. This research focused on GSTM1 gene polymorphisms in Han patients with osteosarcoma, and found that the GSTM1 (-) genotype exists in normal subjects, while osteosarcoma patients 
carry the GSTM1 homozygous deletion subtype. The risk of developing osteosarcoma increased by 2.72 times. A combination of the GSTM1 homozygous deletion subtype and the CYP1A1 Val/ Val genotype may increase risk of osteosarcoma by up to 8.5 times, which proves the existence of a synergy effect. The results also suggest that simultaneous variation in the genes may cause the accumulation of carcinogens in the liver, thus promoting the occurrence of osteosarcoma.

Environmental carcinogens play an important role in carcinogenesis. Polymorphisms in the genes encoding metabolic enzymes GSTM1 and CYP1A1 affect carcinogen activation and deactivation. Our results showed that polymorphisms in the CYP1A1 and GSTM1 genes are susceptibility factors for bone tumors, and allelic variation in these polymorphisms increases risk. The results also suggest that CYP1A1 and GSTM1 gene polymorphisms may be susceptibility indices for bone tumor, and could be used for screening susceptible people and prevention of osteosarcoma by early intervention.

\section{Conflicts of interest}

The authors declare no conflict of interest.

\section{ACKNOWLEDGMENTS}

We thank the anonymous reviewers for reviewing this manuscript.

\section{REFERENCES}

Abu-Amero KK, Al-Boudari OM, Mohamed GH and Dzimiri N (2006). T null and M null genotypes of the glutathione S-transferase gene are risk factor for CAD independent of smoking. BMC Med. Genet. 7: 38.

Amundadottir LT, Thorvaldsson S, Gudbjartsson DF, Sulem P, et al. (2004). Cancer as a complex phenotype: pattern of cancer distribution within and beyond the nuclear family. PLoS Med. 1: e65.

Beer TM, Evans AJ, Hough KM, Lowe BA, et al. (2002). Polymorphisms of GSTP1 and related genes and prostate cancer risk. Prostate Cancer Prostatic Dis. 5: 22-27.

Chou AJ and Gorlick R (2006). Chemotherapy resistance in osteosarcoma: current challenges and future directions. Expert Rev. Anticancer Ther. 6: 1075-1085.

Gonzalez FJ and Yu AM (2006). Cytochrome P450 and xenobiotic receptor humanized mice. Annu. Rev. Pharmacol. Toxicol. 46: 41-64.

Gorlick R, Anderson P, Andrulis I, Arndt C, et al. (2003). Biology of childhood osteogenic sarcoma and potential targets for therapeutic development: meeting summary. Clin. Cancer Res. 9: 5442-5453.

Hayes JD and Strange RC (2000). Glutathione S-transferase polymorphisms and their biological consequences. Pharmacology 61: 154-166.

Jaffe N (2009). Adjuvant chemotherapy in osteosarcoma: an odyssey of rejection and vindication. Cancer Treat. Res. 152: 219-237.

Jonsson S, Thorsteinsdottir U, Gudbjartsson DF, Jonsson HH, et al. (2004). Familial risk of lung carcinoma in the Icelandic population. JAMA 292: 2977-2983.

Kidd LC, Woodson K, Taylor PR, Albanes D, et al. (2003). Polymorphisms in glutathione-S-transferase genes (GST-M1, GST-T1 and GST-P1) and susceptibility to prostate cancer among male smokers of the ATBC cancer prevention study. Eur. J. Cancer Prev. 12: 317-320.

Kiyohara C, Nakanishi Y, Inutsuka S, Takayama K, et al. (1998). The relationship between CYP1A1 aryl hydrocarbon hydroxylase activity and lung cancer in a Japanese population. Pharmacogenetics 8: 315-323.

Kote-Jarai Z, Easton D, Edwards SM, Jefferies S, et al. (2001). Relationship between glutathione S-transferase M1, P1 and T1 polymorphisms and early onset prostate cancer. Pharmacogenetics 11: 325-330.

Larsen JE, Colosimo ML, Yang IA, Bowman R, et al. (2005). Risk of non-small cell lung cancer and the cytochrome P4501A1 lle462Val polymorphism. Cancer Causes Control 16: 579-585.

Mannervik B and Danielson UH (1988). Glutathione transferases-structure and catalytic activity. CRC Crit. Rev. Biochem. 23: 283-337. 
Marchand LL, Wilkinson GR and Wilkens LR (1999). Genetic and dietary predictors of CYP2E1 activity: a phenotyping study in Hawaii Japanese using chlorzoxazone. Cancer Epidemiol. Biomarkers Prev. 8: 495-500.

Masson LF, Sharp L, Cotton SC and Little J (2005). Cytochrome P-450 $1 \mathrm{~A} 1$ gene polymorphisms and risk of breast cancer: a HuGE review. Am. J. Epidemiol. 161: 901-915.

Mitra AP, Datar RH and Cote RJ (2006). Molecular pathways in invasive bladder cancer: new insights into mechanisms, progression, and target identification. J. Clin. Oncol. 24: 5552-5564.

Nakazato H, Suzuki K, Matsui H, Koike H, et al. (2003). Association of genetic polymorphisms of glutathione-S-transferase genes (GSTM1, GSTT1 and GSTP1) with familial prostate cancer risk in a Japanese population. Anticancer Res. 23: 2897-2902.

Ottaviani G and Jaffe N (2009). The epidemiology of osteosarcoma. Cancer Treat. Res. 152: 3-13.

Sánchez-Tilló E, Liu Y, de Barrios O, Siles L, et al. (2012). EMT-activating transcription factors in cancer: beyond EMT and tumor invasiveness. Cell Mol. Life Sci. 69: 3429-3456.

Schabath MB, Hernandez LM, Wu X, Pillow PC, et al. (2005). Dietary phytoestrogens and lung cancer risk. JAMA 294: 1493-1504.

Taningher M, Malacarne D, Izzotti A, Ugolini D, et al. (1999). Drug metabolism polymorphisms as modulators of cancer susceptibility. Mutat. Res. 436: 227-261.

Wang LD, Zheng S, Liu B, Zhou JX, et al. (2003). CYP1A1, GSTs and mEH polymorphisms and susceptibility to esophageal carcinoma: study of population from a high- incidence area in north China. World J. Gastroenterol. 9: 1394-1397.

Wittig JC, Bickels J, Priebat D, Jelinek J, et al. (2002). Osteosarcoma: a multidisciplinary approach to diagnosis and treatment. Am. Fam. Physician 65: 1123-1132.

Yang CX, Matsuo K, Wang ZM and Tajima K (2005). Phase I/II enzyme gene polymorphisms and esophageal cancer risk: a meta-analysis of the literature. World J. Gastroenterol. 11: 2531-2538.

Yang M, Choi Y, Hwangbo B and Lee JS (2007). Combined effects of genetic polymorphisms in six selected genes on lung cancer susceptibility. Lung Cancer 57: 135-142. 